\title{
Questions, Questions, Questions, and More Questions
}

\section{Kay Gillespie ${ }^{1}$}

Published online: 6 April 2020

(C) Springer Nature B.V. 2020

As we prepare to send this issue of the journal off to press, we find ourselves in a crisis of unprecedented nature because of Covid-19. How do we deal with this situation? How do we deal with our personal situations, perhaps needing to give comfort to loved ones, to family members? How do we deal with the physical closure of our institutions, with the likelihood of no more face-to-face classes for most of us for this term and perhaps beyond? How do we prepare ourselves to offer classes on line when we have not been doing so? How do we conduct research and write when we are distracted, perhaps by the crisis itself and perhaps by our partners and children being at home with us? How do our instructional technology personnel deal with having to help us figure out what to do? How do we deal with the impact on colleagues, neighbors, the persons we know at our grocery stores, servers whom we may recognize and know at our favorite restaurants? We have so many questions, questions, questions, and then even more questions? Our world has gone topsy-turvy in just a few short weeks.

As educators and scholars do we have a responsibility to seek to distance ourselves emotionally from all that is going on, to bring reason and knowledge and good information to bear upon the problems as we go forward? I think we do. However, at the same time we must also balance that reasoned distance with our emotions. We do not have time to analyze in depth everything that is swirling about us. We must choose to act and choose how we act in both our personal and professional spheres. We cannot stand back and wait. We cannot engage in non-action. Are we in a Kafkaesque situation, do we just finally give in to total despair and die like Joseph K. in The Metamorphosis?

A resounding NO is the answer to that last question. As educators and scholars, no matter what our disciplines may be, questions are our business! Seldom do we find the definitive answer to the most important questions, but our thoughts and our interactions with others take us to another level of questions and of knowledge acquisition or knowledge-challenge.

Certainly one fallback strategy is to consider the lessons of history. Whatever our ages may be, we can look back on crises which we have experienced ourselves or about which we have heard or read and remember that these crises made us fearful and led to feelings of being disconcerted. Sometimes we felt as though our foundations had crumbled. For some of us that

Kay Gillespie 
might even go back to the devastation brought about by the Second World War, to the horrors of Hiroshima. We dealt with the problems that arose after the Second World War due to the G.I. Bill, which had a tremendous positive impact on higher education and on society at large. Moving forward in history, we lived through the Cold War; we engaged in "duck and cover" in our elementary schools. We saw video clips of the battle of Pork Chop Hill that occurred during the Korean "police action," and then we simultaneously laughed and wept as we watched the re-creation of that conflict in the TV series "M.A.S.H. Many of us experienced the disturbances of the $60 \mathrm{~s}$, the fracturing of society, the meanness and horror of the Vietnam era as encapsulated in the image of the naked young girl fleeing from a Napalm attack, the efforts to gain civil rights - a battle that is ongoing. We can add to this list the Gulf War, the conflict in Afghanistan, the other wars, and the increase in expressions of hatred and "othering." We read about and see images of terrible conflicts around the world; they are heaped upon us on a daily basis. When one makes such a list, it is really depressing.

I think of our young people, our children, our grandchildren, and our students, some of whom we may not see again face-to-face. Are they feeling scared, are they feeling as though their foundations have crumbled? How can we comfort them? Perhaps we can, for ourselves and others, consider the lessons from history. Yes, horrible things have happened. Yes, lives have been disrupted, and people have died. However, we have managed to come through these conflicts - wounded and scarred though we may be. Society is always changed in some way. There will be a new normal.

Questions, questions, questions, and more questions! Can we stand back from the crisis now swirling about us? Can we seek our own reasoned response on both personal and professional levels to the problems? Can we encourage others in tactful ways to also seek reasoned response? Can we fight the baser side of us and seek to nurture and express caring for others in difficult situations? Can we express that same kind of caring for ourselves?

I believe that we can do so, and I believe that we must do so. That is our responsibility as higher education professionals and as citizens and as individuals.

Publisher's Note Springer Nature remains neutral with regard to jurisdictional claims in published maps and institutional affiliations. 